\title{
Intracerebral Hemorrhage Secondary to Envenomation by Viper Bite: Case Report and Review of the Literature
}

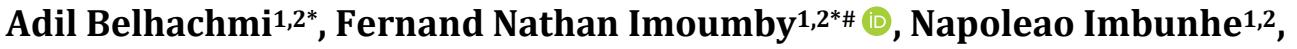 \\ Yao Christian Hugues Dokponou ${ }^{1,2}$ (), Suzanne Rita Aubin Igombe ${ }^{2,3}$, Miloudi Gazzaz ${ }^{1,2}$ \\ ${ }^{1}$ Mohammed V Military Teaching Hospital, Rabat, Morocco \\ ${ }^{2}$ Faculty of Medicine and Pharmacy, Mohammed V University, Rabat, Morocco \\ ${ }^{3}$ Department of Radiology, Mohammed V Military Teaching Hospital, Rabat, Morocco \\ Email: abelhachmi510@gmail.com, "ifernandnathan@gmail.com, imbunhe@gmail.com, dokponou2407@gmail.com, \\ sueaubin1986@gmail.com,gmiloneuro@yahoo.fr
}

How to cite this paper: Belhachmi, A., Imoumby, F.N., Imbunhe, N., Dokponou, Y.C.H., Aubin Igombe, S.R. and Gazzaz, M. (2021) Intracerebral Hemorrhage Secondary to Envenomation by Viper Bite: Case Report and Review of the Literature. Open Access Library Journal, 8: e7495.

https://doi.org/10.4236/oalib.1107495

Received: May 6, 2021

Accepted: June 20, 2021

Published: June 23, 2021

Copyright $\odot 2021$ by author(s) and Open Access Library Inc.

This work is licensed under the Creative Commons Attribution International License (CC BY 4.0).

http://creativecommons.org/licenses/by/4.0/

\section{(c) (i) Open Access}

\begin{abstract}
The envenomations by viper bites are frequent and constitute the prerogative of rural areas in Morocco, as in the tropical countries of Asia, the Maghreb, and sub-Saharan Africa. Children are often more affected than adults, with morbidity and mortality which makes it a major public health problem. The physiopathological mechanisms associated with it are complex, resulting in a wide variety of clinical presentations among which coagulation disorders are prominent, involving all devices either individually or in the context of systemic involvement (Intravascular coagulation disseminated). We report the case of a 62-year-old patient, with no pathological history, victim of envenomation by the bite of a viper, quickly taken to the emergency room and immediately taken care of, who secondarily presented a sudden worsening of his neurological state related to an intracerebral hemorrhage documented by the brain CT-Scan, in a context of disseminated intravascular coagulation. Despite the speed and quality of the treatment, the patient died within 24 hours.
\end{abstract}

\section{Subject Areas \\ Public Health}

\section{Keywords}

Hematoma, Intracerebral, Envenomation, Viper 


\section{Introduction}

Spontaneous intracerebral hematoma (HIS) is common in neurosurgical practice and according to Sutherland et al. [1], it represents $15 \%$ of all strokes in the North American and European populations. It is more often of interest to men than women and its incidence increases with age [2]. More frequently localized at the level of the Putamen (gray nuclei) its clinical presentation varies according to the size and the site [3]. The aetiologies are represented by arterial hypertension, amyloid angiopathy, drug-induced or coagulopathy-related crase abnormalities, and ruptures of vascular malformations dominated by arteriovenous malformations and aneurysms. The world health organization estimates that 125,000 people per year die worldwide from envenomation after a snakebite [4]. These envenomations are associated with significant morbidity and mortality. Although rare in Western countries, they constitute a real public health problem in tropical countries [5]. Coagulation disorders are frequently associated with them, and in the literature there are some papers which report the occurrence of intracerebral hemorrhage secondary to envenomation [4] [6]. We report here the case of a 62-year-old patient with no clinical history, victim of envenomation by the bite of a viper, who secondarily presented a spontaneous intracerebral hemorrhage, which occurred in a context of disseminated intravascular coagulation (DIC) with a rapidly fatal outcome despite the prophylactic and therapeutic measures implemented. This work has two purposes; first establish a causal link between the occurrence of intracerebral hemorrhage and snakebite envenomation, then conduct a review of the literature.

\section{Case Presentation}

This is a 62-year-old patient with no medical history who was taken to the ZAGORA emergency room following a viper bite. Housewife, living on the outskirts of ZAGORA $40 \mathrm{~km}$ from TINZOULINE in southern MOROCCO, she was allegedly bitten by a viper accidentally in the left ankle. Neighbors say they found a horned viper on site (Figure 1). On arrival at the emergency room: the patient presented with vomiting, headache and left hemiparesis and the initial examination noted local edema of the left ankle with bite marks (Figure 2). On admission, she was fully conscious with a stable hemodynamic state. The initial biology was strictly normal. The patient received immediately over 20 minutes an intravenous infusion of FAV-Afrique ${ }^{\circledR}$ antivenom serum at a dose of six ampoules associated with volume expansion by crystalloids, antibiotic therapy with amoxicillin-clavulanic acid, analgesia with paracetamol and local care at the level. Of the bite. She also received heparin calcium in prophylactic doses. She was admitted to the emergency room. Six hours after admission, she presented abruptly with an altered state of consciousness with a Glasgow score of 06, a bilateral Babinski sign, right anisocoria and decerebration stiffness. She presented with a drop in blood pressure with a BP of 70/35 $\mathrm{mmHg}$, cold extremities and mottling. Locally, there was an extension of the edema to the entire left lower 

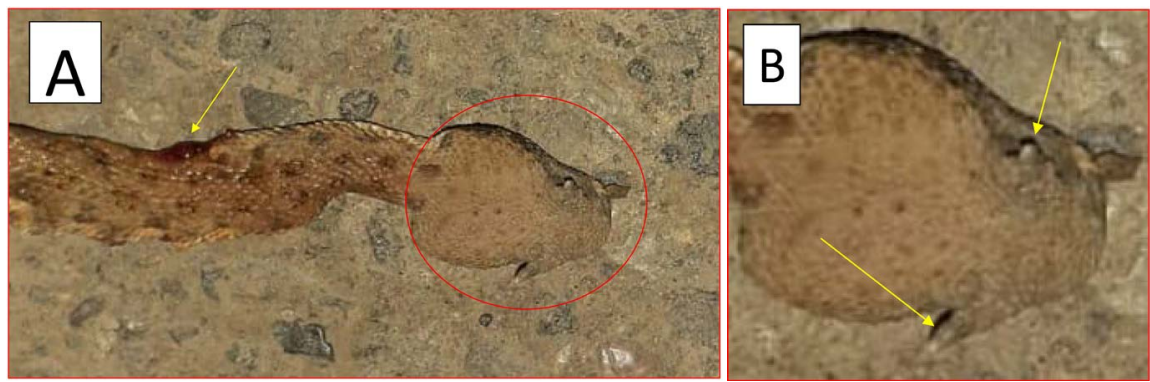

Figure 1. Horned viper: Cerastes cerastes (A and B) whose horns are designated by the yellow arrows (B). We see the bleeding next to the point of impact which was fatal to him, following the bite of our patient (A-yellow arrow).

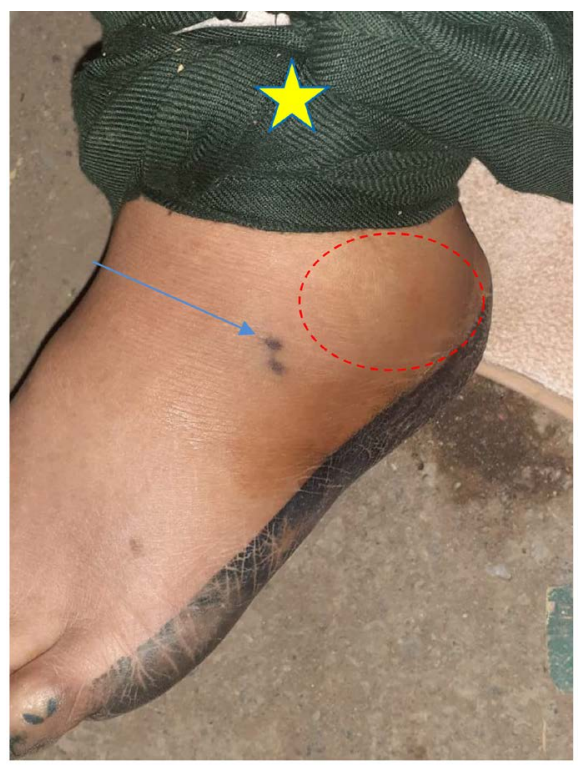

Figure 2. Bite marks (blue arrow), with the ankle which appears swollen (red dotted lines), and a traditional tourniquet (yellow star).

limb. The laboratory assessment performed at 6 hours, showed an acute anemia with hemoglobin at $7 \mathrm{~g} / \mathrm{dl}$, thrombocytopenia at 40,000 elements $/ \mathrm{mm}^{3}$ and a collapsed PT at $40 \%$. The remainder of the hemostasis workup found fibrinogen below 0.3 and fibrin degradation products (PDF) present. The brain scan without injection performed urgently revealed a right intracerebral hematoma with diffuse subarachnoid hemorrhage (Figure 3), and a falcoriel engagement. The outcome was rapidly unfavorable with the death of the patient within 24 hours of the bite.

\section{Discussion}

In Morocco, seven snake species belonging to the viparidae family (Daboia mauritanica, bitis arietans, Cerastes cerastes, cerastes vipera, Echis leucogaster, vipera latastei, vipera monticola), and one to that of elapids (Naja haje legionis) are poisonous and present a mortal danger to humans [7]. Our patient was the victim of a horned viper (Cerastes cerastes). In the case of vipers, and in particular 


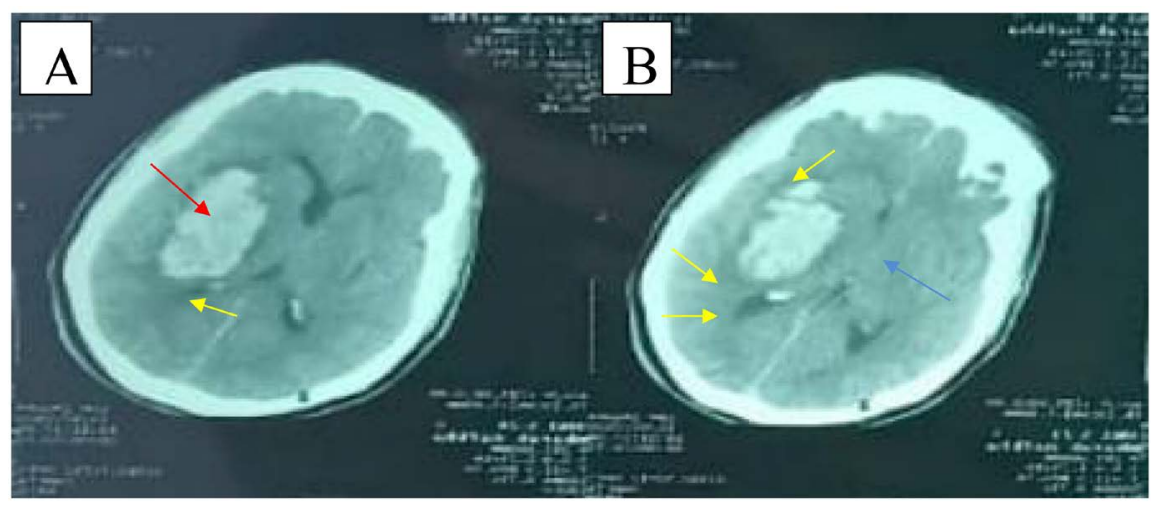

Figure 3. A C-cerebral CT scan (A, B) showing a deep hematoma (red arrow-A) of the gray nuclei on the right side surrounded by a peri-lesional edema (yellow arrows-A, B) and exerting a mass effect on the midline (blue arrow-B), with disappearance of the cortical furrows associated with diffuse subarachnoid hemorrhage.

of the horned viper, neurotoxicity is indirect and induced by tissue damage and disturbances of hemostasis generated by enzymes. The venom of Cerastes cerastes contains several pro-coagulant proteins: cerastocytin, and cerastobin. It also contains cerastase, cerastatin, cerastin and cerastotin which can give thrombocytopenia and hypofibrinogenemia [8]. These disturbances can explain the occurrence of hemorrhagic vascular accidents as in the case of our patient, as well as the picture of disseminated intravascular coagulation which is associated with it. It has also been reported that the occurrence of an intracerebral hematoma after envenomation by snakebite was linked either to late and poor quality management, or to the occurrence of severe coagulopathy [9] [10], which applies in part to our patient because of her disseminated intravascular coagulation picture. Intracerebral haemorrhages after a pseudonaja bite in Australia have been associated with subcutaneous or intravenous adrenaline, administered routinely for the prophylaxis of adverse reactions to anti-venomous serum [4] [11]. However, later controlled and randomized studies questioned the real role of adrenaline in this type of bleeding [12]. At this stage, it should be noted that the hemorrhagic complications related to hemostasis disorders in the event of envenomation by viper bite, can concern any organ with the same level of lethality as several papers have reported [13] [14]. Although it is common to observe the occurrence of intracerebral hematomas during envenomation by viperids as pointed out by several authors [4] [5], some papers in the literature have linked to them, on the contrary, rare cases of ischemic strokes [15]-[21]. Our patient received an intravenous infusion of FAV Afrique, which constitutes a polyvalent antidote, not specific for horned vipers. Despite the rapidity of the treatment and the many therapies associated with this anti-venom, the evolution has been inexorably worsening. The ideal treatment when the viper or the snake is formally identified, is based on the administration of a monovalent or an anti-venom specific to the identified snake, which has the benefit of inoculating the patient with lower doses of anti-protein. venom than with versatile anti-venom [22]. Great regional 
variation has been reported in the composition of the venom [22] [23], therefore it is recommended to use a locally produced anti-venomous serum, specific to the region to avoid treatment failures. Phillips et al. reported that the antivenom developed for Indian vipers did not work when used for Sri Lankan viper bites [22] [24]. Our patient came from a rural area, and the promptness of treatment did not prevent the outcome of her death in less than 24 hours. Which accounts for the seriousness of his painting. Indeed, some authors have reported that death within the first 24 hours was exceptional and that often patients who died were brought to hospital beyond 72 hours after the bite of the viper. Several studies carried out in India have attributed the high mortality in this country to geographical factors as well as the rural predominance of a population dependent on agriculture [25] [26].

\section{Conclusion}

The envenomations by viper bite are relatively frequent in tropical zones and known to induce important anomalies of the blood crase, being able to go up to the occurrence of an intracerebral hematoma. Through this case study, we see that it would be appropriate to consider the local production of anti-venomous serum given the territorial variations of the venoms already described in the literature.

\section{Author Contributions}

Fernand Nathan IMOUMBY: Conceptualization, Writing an original draft, \& editing. Adil BELHACHMI: Writing, review \& editing. Napoleao IMBUNHE: Writing, review \& editing. Yao Christian Hugues Dokponou: Writing, review \& editing. Suzanne Rita AUBIN IGOMBE: Writing, review \& editing. Miloudi

GAZZAZ: Supervision, review \& validation.

\section{Ethics}

Informed consent and verbal permission were obtained from the family of the patient prior to the submission of this article.

\section{Acknowledgements}

We thank the staff of the emergency department of the Zagora hospital, with whom we worked on the elaboration of this paper.

\section{Conflicts of Interest}

The authors declare not having any conflict of interest in this case report and there are no financial resources.

\section{References}

[1] Sutherland, G.R. and Auer, R.N. (2006) Primary Intracerebral Hemorrhage. Journal of Clinical Neuroscience, 13, 511-517. https://doi.org/10.1016/j.jocn.2004.12.012 
[2] Broderick, J.P., Brott, T., Tomsick, T., Miller, R. and Huster, G. (1993) Intracerebral Hemorrhage More than Twice as Common as Subarachnoid Hemorrhage. Journal of Neurosurgery, 78, 188-191. https://doi.org/10.3171/jns.1993.78.2.0188

[3] An, S.J., Kim, T.J. and Yoon, B.-W. (2017) Epidemiology, Risk Factors, and Clinical Features of Intracerebral Hemorrhage: An Update. Journal of Stroke, 19, 3-10. https://doi.org/10.5853/jos.2016.00864

[4] Pinho, F.M.O. and de Almeida Burdmann, E. (2001) Fatal Cerebral Hemorrhage and Acute Renal Failure after Young Bothrops jararacussu Snake Bite. Renal Failure, 23, 269-277. https://doi.org/10.1081/JDI-100103499

[5] Bartholdi, D., Selic, C., Meier, J. and Jung, H. (2004) Viper Snakebite Causing Symptomatic Intracerebral Haemorrhage. Journal of Neurology, 251, 889-891. https://doi.org/10.1007/s00415-004-0446-8

[6] Ghezala, H.B. and Snouda, S. (2015) Accident vasculaire cérébral hémorragique mortel suite à une envenimation par une vipère à corne en Tunisie. The Pan African Medical Journal, 21, Article No. 156.

https://doi.org/10.11604/pamj.2015.21.156.6401

https://www.ncbi.nlm.nih.gov/pmc/articles/PMC4546793/

[7] El Hattimy, F., Fouad, C., Soulaymani, A. and Bencheikh, R. (2016) Envenimations Ophidienne chez l'enfant au Maroc: Aspects épidémiologiques, et facteurs de risque. Research Fr, 3, 1513.

[8] Marrakchi, N., Zingali, R.B., Karoui, H., Bon, C. and el Ayeb, M. (1995) Cerastocytin, a New Thrombin-Like Platelet Activator from the Venom of the Tunisian Viper Cerastes cerastes. Biochimica et Biophysica Acta (BBA)-General Subjects, 1244, 147-156. https://doi.org/10.1016/0304-4165(94)00216-K

[9] Mirtschin, P.J. (1991) Fatal Cerebral Haemorrhage after Snake Bite. Medical Journal of Australia, 155, 850-851. https://doi.org/10.5694/j.1326-5377.1991.tb94067.x

[10] Sprivulis, P. and Jelinek, G.A. (1995) Fatal Intracranial Haematomas in Two Patients with Brown Snake Envenomation. Medical Journal of Australia, 162, 215-216. https://doi.org/10.5694/j.1326-5377.1995.tb126029.x

[11] Midyett, F.A. (1998) Neuroradiologic Findings in Brown Snake Envenomation: Computed Tomography Demonstration. Australasian Radiology, 42, 248-249. https://doi.org/10.1111/j.1440-1673.1998.tb00508.x

[12] Premawardhena, A.P., De Silva, C.E., Fonseka, M.M.D., Gunatilake, S.B. and De Silva, H.J. (1999) Low Dose Subcutaneous Adrenaline to Prevent Acute Adverse Reactions to Antivenom Serum in People Bitten by Snakes: Randomised, Placebo Controlled Trial. BMJ, 318, 1041-1043. https://doi.org/10.1136/bmj.318.7190.1041

[13] Palangasinghe, D.R., Weerakkody, R.M., Dalpatadu, C.G. and Gnanathasan, C.A. (2015) A Fatal Outcome Due to Pulmonary Hemorrhage Following Russell's Viper Bite. Saudi Medical Journal, 36, 634-637. https://doi.org/10.15537/smj.2015.5.10691

[14] Rathnayaka, R.N., Ranathunga, P.N. and Kularatne, S.A.M. (2019) Systemic Bleeding Including Pulmonary Haemorrhage Following Hump-Nosed Pit Viper ( $\mathrm{Hyp}_{\mathrm{p}}$ nale hypnale) Envenoming: A Case Report from Sri Lanka. Toxicon, 170, 21-28. https://doi.org/10.1016/j.toxicon.2019.09.009

[15] Hoskote, S.S., Iyer, V.R., Kothari, V.M. and Sanghvi, D.A. (2009) Bilateral Anterior Cerebral Artery Infarction Following Viper Bite. Journal of the Association of Physicians of India, 57, 67-69.

[16] Pal, J., Mondal, S., Sinha, D., Ete, T., Chakraborthy, A., Nag, A., et al. (2014) Cerebral Infarction: An Unusual Manifestation of Viper Snake Bite. International Journal of Medical Sciences, 2, 1180-1183. 
https://doi.org/10.5455/2320-6012.ijrms20140836

[17] Narang, S.K., Paleti, S., Asad, M.A. and Samina, T. (2009) Acute Ischemic Infarct in the Middle Cerebral Artery Territory Following a Russell's Viper Bite. Neurology India, 57, 479-480. https://doi.org/10.4103/0028-3886.55594

[18] Gouda, S., Pandit, V., Seshadri, S., Valsalan, R. and Vikas, M. (2011) Posterior Circulation Ischemic Stroke Following Russell's Viper Envenomation. Annals of Indian Academy of Neurology, 14, 301-303. https://doi.org/10.4103/0972-2327.91957

[19] Deepu, D., Hrishikesh, S., Suma, M.T. and Zoya, V. (2011) Posterior Fossa Infarct Following Viper Bite: A Paradox. Journal of Venomous Animals and Toxins including Tropical Diseases, 17, 358-360. https://doi.org/10.1590/S1678-91992011000300017

[20] Ittyachen, A.M. and Jose, M.B. (2012) Thalamic Infarction Following a Russell's Viper Bite. Southeast Asian Journal of Tropical Medicine and Public Health, 43, 1201-1204.

[21] Lee, B., Hwang, S.-H., Bae, J.-C. and Kwon, S.-B. (2001) Brainstem Infarction Following Korean Viper Bite. Neurology, 56, 1244-1245.

https://doi.org/10.1212/WNL.56.9.1244

[22] Monteiro, F.N.P., Kanchan, T., Bhagavath, P., Kumar, G.P., Menezes, R.G. and Yoganarasimha, K. (2012) Clinico-Epidemiological Features of Viper Bite Envenomation: A Study from Manipal, South India. Singapore Medical Journal, 53, 203-207.

[23] Warrell, D.A. (2010) Guidelines for the Management of Snake-Bites. World Health Organization, Geneva.

[24] Phillips, R.E., Theakston, R.D.G., Warrell, D.A., Galigedara, Y., Abeysekera, D., Dissanayaka, P., et al. (1988) Paralysis, Rhabdomyolysis and Haemolysis Caused by Bites of Russell's Viper (Vipera russelli pulchella) in Sri Lanka: Failure of Indian (Haffkine) Antivenom. QJM: An International Journal of Medicine, 68, 691-715.

[25] Kulkarni, M.L. and Anees, S. (1994) Snake Venom Poisoning: Experience with 633 Cases. Indian Pediatrics, 31, 1239-1239.

[26] Sharma, N., Chauhan, S., Faruqi, S., Bhat, P. and Varma, S. (2005) Snake Envenomation in a North Indian Hospital. Emergency Medicine Journal, 22, 118-120. https://doi.org/10.1136/emj.2003.008458 